\title{
MANEJO DA RESISTÊNCIA: NA ERA DAS PLANTAS TRANSGÊNICAS
}

\author{
Vilmar Machado* \& Lidia Mariana Fiuza
}

Universidade do Vale do Rio dos Sinos, Centro de Ciências da Saúde, Programa de Pós-Graduação em Biologia - Laboratório de Microbiologia. Avenida Unisinos, 950. CEP: 93022-000. São Leopoldo - RS.

E-mails: vmachado27@hotmail.com, fiuza@unisinos.br

\section{RESUMO}

A evolução da resistência das pragas-alvo aos agentes de controle é uma das preocupações dos agentes envolvidos nos sistemas de produção agrícola. O manejo da resistência refere-se a um conjunto de procedimentos aplicados em áreas agrícolas com a finalidade de evitar e/ou retardar a evolução da resistência das pragas aos agentes empregados no seu controle. A evolução da resistência de insetos aos agentes de controle é de grande relevância, ligando áreas como a ecologia, a genética e a economia. Com o surgimento e o cultivo das plantas $B t$, as pesquisas e trabalhos nesse campo tornaram-se cada vez mais importantes e são essenciais à manutenção da produtividade destas culturas. O manejo da evolução da resistência às plantas $B t$ é uma questão com vários aspectos polêmicos tanto do ponto de vista prático como teórico. A principal estratégia aplicada para "manejar" a evolução da resistência às plantas $B t$ é denominada de "altas doses e refúgios estruturados". Além disso, é de extrema relevância a aplicação de métodos de monitoramento das populações procurando detectar a presença ou o aumento na frequência de insetos resistentes. Nesse contexto é fundamental compreender quais princípios biológicos são utilizadas para substanciar as estratégias de manejo adotadas e quais as principais incertezas associadas à aplicação generalizada dos mesmos. O que acontecerá se a resistência não for determinada por genes recessivos ou quando os cruzamentos entre os indivíduos resistentes e susceptíveis não ocorrer de forma aleatória? Um dos pontos importantes das estratégias de manejo da resistência é o monitoramento das áreas de cultivo com o objetivo de detectar a presença de insetos resistentes. A eficiência dos métodos de monitoramento depende da sua capacidade de detectar a presença do alelo que confere resistência enquanto sua freqüência for muito baixa (em geral, inferior a 0,001). Entre esses métodos destacam-se os bioensaios de dose resposta, bioensaios de diagnóstico e triagem de F2. A compreensão de todos os aspectos envolvidos no manejo e monitoramento da evolução da resistência é essencial para entender porque nossa relação evolutiva com os insetos-praga pode ser comparada a uma "corrida ao armamento". Além disso, possibilita compreender porque o manejo da resistência é considerado um dos grandes problemas que ligam ecologia, evolução e economia na atualidade.

Palavras-chave: Plantas $B t$; manejo da resistência; altas doses; refúgios; monitoramento.

\section{ABSTRACT}

RESISTANCE MANAGEMENT: IN TRAGENIC PLANTS AGE. The evolution of resistance of many target pests to the chemical control agents is a constant concern of farmers and agricultural workers. The development of resistance is usually controlled by a number of procedures applied to the agricultural land to overcome or reduce the resistance of the pests to the control agents utilized. The form of evolution of the insect's resistance to the control agents is of considerable relevance and involves ecological, genetic and economic aspects. When $B t$ plants were developed and widely cultivated, research and studies in this field became more and more important and are now essential for the maintenance of productivity of these cultures. The management of the evolution of the resistance of the $B t$ plants is a question with many polemical aspects, from both practical and theoretical standpoints. The principal strategy applied to "manage" the evolution of the resistance of the Bt plants is known as "high doses - structured refuge". Also, it is of considerable importance 
that methods of monitoring the plant populations are implemented to detect the presence, or an increase in the numbers, of resistant insects. In this context the underlying biological principles that are employed to substantiate the management strategy adopted must be clearly understood and the principal uncertainties associated with generalized applications recognized. What would happen if the resistance was determined by recessive genes, or when the crossing of resistant and susceptible individuals does not happen in a random manner? One of the important points in the strategy of resistance management is to monitor the cultivated areas with the objective of detecting the presence of resistant insects. The efficiency of the monitoring methods depends on their capacity to detect the presence of the allele that confers resistance while the frequency is still very low (in general less than 0.001). Among these methods, bio-testing the response dose, diagnosis biotesting and the characterization of F2 are considered best. A clear understanding of all the aspects involved in managing and monitoring the evolution of the resistance is essential because our evolutionary relation with the insect pests can be compared to an armament race. Also, it becomes possible to understand why resistance management is considered one of the great problems linking ecology, evolution and economy at the present time.

Keywords: Bt-crops; resistance management; high doses; structured refugee; monitoring.

\section{RESUMEN}

MANEJO DE RESISTENCIA: LA ERA DE LAS PLANTAS TRANSGÉNICAS. El desarrollo de resistencia de plagas a los agentes de control es una preocupación de los implicados en sistemas de producción agrícola. El manejo de resistencia se refiere a un conjunto de procedimientos aplicados en los sitios agrícolas con el objetivo de evitar o retrasar el desarrollo de resistencia de plagas a los agentes empleados en su control. El desarrollo de resistencia a los agentes de control de insectos es de gran importancia, conectando áreas como la ecología, la genética y la economía. Con el surgimiento y el cultivo de plantas Bt, la investigación científica y los trabajos en esta área son cada vez más importantes y esenciales para mantener la productividad de estos cultivos. La gestión del desarrollo de resistencia a plantas Bt es un tema con diversos aspectos polémico tanto prácticos como teóricos. La principal estrategia empleada para "manejar" el desarrollo de resistencia a plantas Bt es llamada de "altas dosis y refugios estructurados." Además, es muy importante la aplicación de métodos de monitoreo de poblaciones para la detección de presencia o ampliación de frecuencia de los insectos resistentes. En este contexto, es fundamental comprender cuales principios biológicos son usados para fundamentar las estrategias de manejo adoptadas y las principales incertidumbres asociadas a la aplicación generalizada de ellos. ¿Qué sucede si la resistencia no está determinada por genes recesivos o cuando los cruzamientos entre individuos resistentes y susceptibles no se producen al acaso? Una de las cosas más importantes de las estrategias de manejo de resistencia es el monitoreo de los sitios de cultivo con el fin de detectar la presencia de insectos resistentes. La eficiencia de los métodos de monitoreo, depende de su capacidad de detectar la presencia del alelo que confiere resistencia, mientras que su frecuencia es demasiado baja (comúnmente menor que 0.001). En estos métodos sobresalen los bioensayos de dosis/respuestas, ensayos de diagnóstico y de detección de F2. La comprensión de todos los aspectos contenidos en el manejo y monitoreo del desarrollo de resistencia es esencial para comprender la razón de nuestra relación con el desarrollo de insectos plagas se permitir comparar a una "carrera armamentista". Además es posible comprender porque el manejo de resistencia es considerado uno de los mayores problemas que unen la ecología, la evolución y la economía actuales.

Palabras clave: Plantas Bt; gestión de resistencia; altas dosis; refugios; vigilancia.

\section{INTRODUÇÃO}

O manejo da resistência refere-se a um conjunto de procedimentos aplicados em áreas agrícolas com a finalidade de evitar ou/e retardar a evolução da resistência das pragas aos agentes empregados no seu controle. Seu desenvolvimento começou ainda na era dos produtos químicos, quando os pesquisadores perceberam que a evolução da resistência por parte dos organismos alvos era uma questão de tempo. Estudos 
realizados nessa época indicaram que a evolução da resistência pode ser retardada pela aplicação de técnicas adequadas de manejo das culturas. Com o advento das plantas transgênicas que expressam genes da bactéria Bacilllus thuringiensis, as pesquisas e trabalhos nessa área se tornaram cada vez mais importantes e são essenciais para a manutenção da produtividade destas culturas (Lemesle 2010).

Um dos principais objetivos do manejo da resistência é evitar que se formem populações de insetos resistentes às toxinas $B t$ produzidas pelas plantas e também que essa resistência se espalhe para outras populações. Essa preocupação é maior à medida que as áreas cultivadas com plantas $\mathrm{Bt}$ crescem por todo o mundo (James 2010).

As primeiras espécies comercializadas contendo genes $B t$ foram milho e algodão; as áreas de cultivo destas espécies cresceram rapidamente aumentando a produtividade e reduzindo no uso de inseticidas (High et al. 2004). Antes mesmo da comercialização destas espécies, a Agência de Proteção Ambiental dos Estados Unidos (US-EPA) responsável pela sua liberação exigiu a definição de estratégias de manejo da resistência que seriam implementadas a partir do ano 2000 nas áreas cultivadas com estas espécies.

Em 1998, como resultado de uma reunião para discutir as estratégias de manejo da resistência, foi recomendada pela US-EPA a adoção da estratégia denominada "altas doses-refúgios estruturado" como uma das melhores opções disponíveis no momento para retardar a evolução da resistência dos insetos a plantas- $B t$. De acordo com a US-EPA as companhias que registram uma planta $B t$ devem fiscalizar a implementação dos planos de manejo e também notificar os agricultores que não cumprem as estratégias estabelecidas, os quais podem por sua vez perder a licença para cultivo de plantas $B t$. Nos Estados Unidos, para obter licença para cultivo de plantas $B t$, os agricultores assumem um compromisso legal de seguir o plano de manejo definido para sua região (US-EPA 2010).

\section{ESTRATÉGIA DE ALTAS DOSES E REFÚGIOS ESTRUTURADOS}

Essa estratégia fundamenta-se em modelos teóricos e testes experimentais realizados em pequena escala (Georghiou \& Taylor 1977, Gould 1998, Peck et al. 1999, Caprio 2001, Onstad et al.
2002; Liu \& Tabashnik 1997, Shelton et al. 2002, Wenes et al. 2006). Esta estratégia está baseada em duas aceitações importantes: a resistência é uma característica recessiva e os cruzamentos entre indivíduos resistentes e não-resistentes ocorre de forma aleatória.

ALTAS DOSES: essa expressão significa que as plantas produzirão quantidades suficientes da toxina $B t$ para eliminar da população os indivíduos que possuem uma única cópia do gene para resistência, ou seja, os heterozigotos. Por definição, "dose alta", é aquela suficiente para matar mais do que 99\% dos insetos heterozigotos (Georghious \& Taylor 1977, Roush 1994, Gould 1988). De acordo com Laxminarayan \& Fischer (2004), essa concentração é aproximadamente 25 vezes maior do que a necessária para matar um indivíduo não-resistente. Essa estratégia torna a resistência uma característica funcionalmente recessiva, uma vez que apenas os portadores de duas cópias do gene sobrevivem às doses de toxina produzida pelas plantas $B t$ (Tabashnik \& Croft 1982). Nas áreas com plantas $B t$, sobreviverão apenas os raros portadores de duas cópias do gene para resistência, ou seja, os homozigotos recessivos. No início da comercialização de plantas $B t$ estimavase que aproximadamente um em cada 1000 insetos poderia ser portador do gene para resistência. Assim, apenas um em 1 milhão seria portador de duas cópias do gene para resistência.

Refúgio é a área na qual não são cultivadas plantas $B t$ e sua finalidade é manter na população indivíduos susceptíveis à toxina $B t$, ou seja, aqueles que não possuem genes para a resistência (Bourguet et al. 2005). Sua contribuição é a produção de um número suficiente de insetos adultos susceptíveis à toxina $B t$ para cruzarem com insetos homozigotos resistentes, "diluindo", dessa forma, a resistência na população. A dispersão para fora das áreas dos refúgios é necessária para que os cruzamentos aconteçam (Figura 1 e Figura 2).

São fatores relevantes na definição da área de refúgio: a capacidade de dispersão da praga, sua biologia reprodutiva e seus hábitos alimentares. A distribuição dos refúgios também procura reduzir a possibilidade de cruzamentos entre indivíduos homozigotos para o gene da resistência (Peck et al. 1999, Caprio 2001, Ives \& Andow 2002, Vacher et al. 2006, Tyutyunov et al. 2007, 2008, Hanur 2008, Gassmann et al. 2009). 
1. As larvas emergem e alimentam-se de plantas

Bt.

5. Os descendentes se reproduzem e depositam seus ovos sobre as plantas Bt e o ciclo reinicia.
4. Os raros individuos resistentes ( $r$ ) cruzam com não-resistente (RR) produzindo descendentes (Rr)

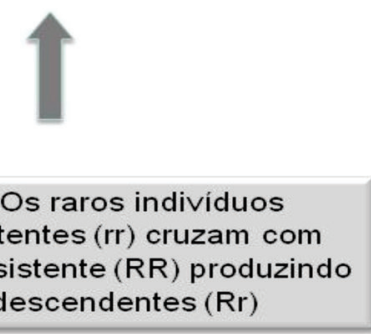

\section{A maioria das larvas morre após a ingestão de plantas Bt.}
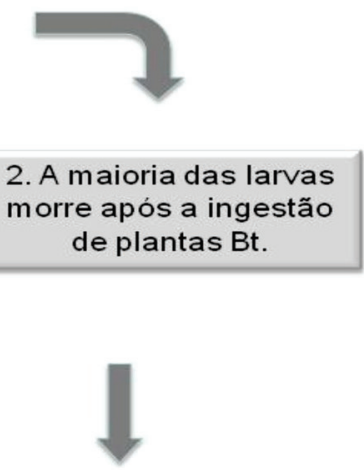

3. Poucos indivíduos resistente (rr) sobrevivem

Figura 1. Esquema básico do manejo da resistência de acordo com a teoria de altas doses e refúgios estruturados. Figure 1. Basic aspects of the resistance management on requirement of the high dose and structured refuge theory.

\section{ESTRATÉ GLA DE ALTAS DOSES-REFÚGIO}

\author{
Não-resistente \\ Não-resistente \\ Resistente
}
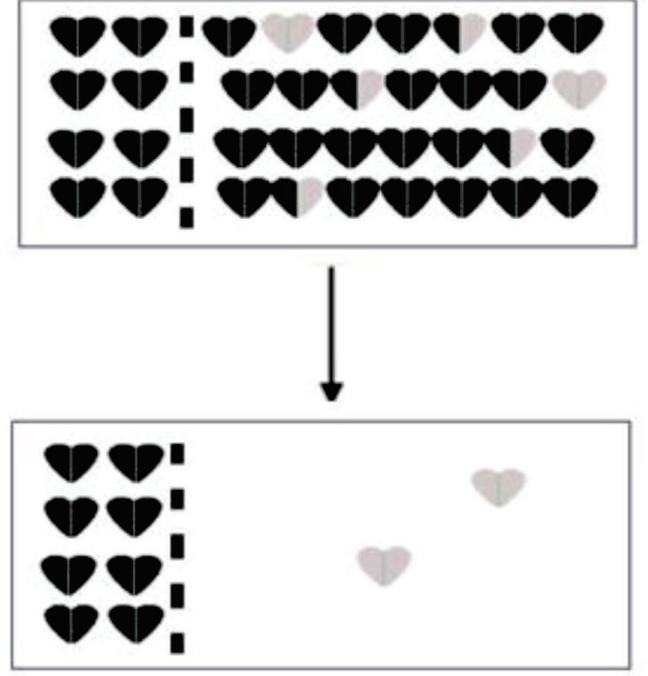

As aceitações dessa estrategia são: o gene para resistência ocorre em freqüência baixa nas populações; as quantidades de toxina Bt produzidas pelas plantas são altas o suficiente para eliminar da população os insetos não resistentes (homozigotos recessivos) e os heterozigotos resistentes e os individuos resistentes (homozigotos dominantes) que nascem nas areas com plantas Bt cruzam aleatoriamente com os individuos não resistentes que nascem nas àreas dos refúgios. A finalidade dos refúgios è manter na população individuos susceptiveis a toxina $\mathrm{Bt}$. ou seja, aqueles que não possuem genes para a resistência. Sua contribuição è a produção de insetos adultos susceptiveis a toxina $\mathrm{Bt}$ para cruzarem com insetos homozigotos resistentes, "diluindo", dessa forma, a resistência na população. A dispersão para fora das áreas dos refugios é necessaria para que os cruzamentos aconteçam.
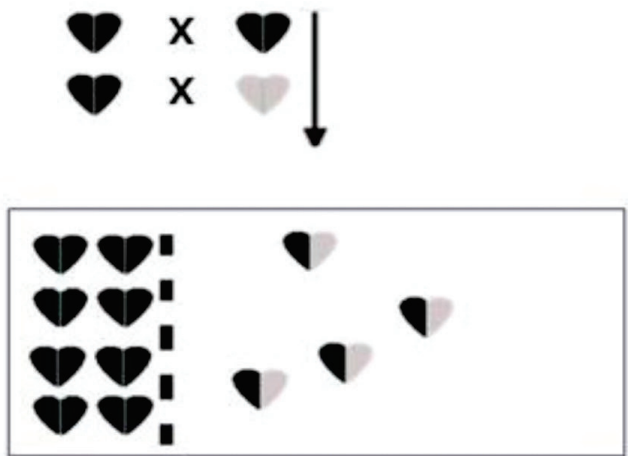

Figura 2. Estratégia de altas doses e refúgios estruturados.

Figure 2. High dose and structured refuge strategy. 
A US-EPA (1998) definiu uma proporção de 500:1 entre insetos não resistentes e resistentes, assumindo, nesse caso, que a frequência do gene para resistência é 0,05 . Além disso, os refúgios devem ser mantidos próximos das áreas com plantas $B t$ para favorecer o cruzamento entre os insetos susceptíveis e os resistentes.

A definição do tamanho das áreas de refúgio é um dos aspectos mais discutidos no manejo da resistência. As dimensões e a distribuição das áreas de refúgio são definidas com base em estudos teóricos e experimentos de campo podendo variar de acordo com a cultura ou praga em questão. A área dos refúgios para milho $B t$ varia entre $20 \%$ e $50 \%$; simulações de computador indicam que áreas menores podem acelerar a evolução da resistência. Para algodão $B t$, por outro lado, recomenda-se que $5 \%$ a $20 \%$ da área de plantio sejam destinadas ao refúgio (Monsanto 2010). Os agricultores lutam para diminuir a extensão dos refúgios, pois os consideram como pontos de menor produção o que, segundo eles, reduz os lucros em cada colheita.

Os refúgios podem estar localizados dentro da área de cultivo com plantas $B t$ ou na suas proximidades. O fundamental é que tenham o tamanho determinado e possibilitem o cruzamento entre os indivíduos ali produzidos com os poucos sobreviventes das áreas com plantas Bt (Figura 3).
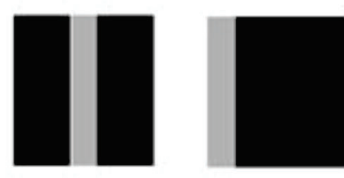

\section{Blocos dentro da área de plantas $\mathrm{Bt}$.}

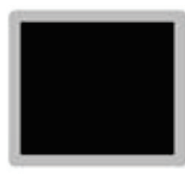

Na periferia da área de plantas Bt.

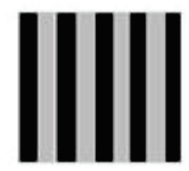

Linhas dentro da área de plantas $\mathrm{Bt}$.

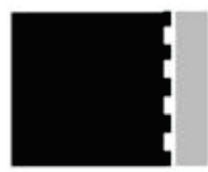

Blocos em áreas adjacentes

Figura 3. Algumas configurações possíveis dos refúgios em áreas de plantas Bt.

Figure 3. Some possible configurations of refuges in the Bt crops areas.
Refúgios para milho Bt

As dimensões do refúgio em plantações de milho $B t$ expressando uma única toxina contra lepidópteros nos Estados Unidos são definidas de acordo com área geográfica na qual a plantação está incluída Existem áreas em que são cultivados milho e algodão $B t \mathrm{e}$ outras onde é cultivado apenas o milho. Em locais onde apenas o milho é cultivado os refúgios deverão ser de $20 \%$ da área plantada com milho $B t$; onde o algodão $B t$ também é cultivado á área destinada ao refúgio será de 50\% (Monsanto 2010). A configuração dos refúgios é flexível e pode ser escolhida pelo agricultor desde que siga alguns critérios básicos. Os procedimentos específicos para cultivo do milho devem ser os mesmos na área de refúgio e naquela que contem plantas $B t$. A variedade de milho utilizada no refúgio deve ser similar àquela utilizada nas áreas com plantas Bt. Quando localizado em área separada, o refúgio não pode estar distante mais que meia milha das plantas Bt. Quando dentro da área com plantas $B t$, o refúgio, pode estar distribuído na forma de um único bloco, no perímetro da plantação, ou distribuído entre as plantas Bt (Vacher et al. 2003).

\section{Refúgio em plantações de algodão Bt (bollgard II)}

Essa variedade é considerada a segunda geração de plantas Bt e expressa as delta-endotoxinas Cry1Ac e Cry2Ab que são altamente específicas e tóxicas a lagartas de alguns lepidópteros, como, Pectinophora gossypiella (Saunders 1844) e Heliothis virescen (Fabricius 1781). De acordo com Li et al. 2006, essas duas proteínas aumentam a durabilidade dessas linhagens de algodão contra a evolução da resistência quando comparadas com as linhagens de algodão expressando apenas uma proteína.

As dimensões dos refúgios para essa variedade foram aprovadas pela Agência de Proteção Ambiental Americana (US-EPA 2001). As opções de refúgios são as seguintes:

a) Refúgios externos não espalhados devem corresponder a $5 \%$ da área plantada com algodão $B t$ e devem estar no máximo a meia milha da plantação. Não podem ser tratados com inseticidas.

b) Refúgios distribuídos dentro da área de cultivo devem ter no mínimo 45,7 metros de largura (91,4 é o desejável) e corresponder a 5\% da área cultivada com 
plantas $B t$. Se a área contendo plantas $B t$ for tratada com inseticidas, os refúgios também devem ser.

c)Refúgios externos espalhados devem corresponder a $20 \%$ da área cultivada com plantas $B t$ e não podem estar distantes mais que uma milha das mesmas. Estes refúgios podem ser tratados com alguns inseticidas.

\section{MONITORAMENTO DA RESISTÊNCIA}

Um dos pontos importantes das estratégias de manejo da resistência é o monitoramento das áreas de cultivo com o objetivo de detectar a presença de insetos resistentes. Se populações resistentes são detectadas quando pequenas será mais fácil tomar medidas para impedir que a resistência se espalhe para outras populações. Amostrar e realizar experimentos com insetos das espécies alvos que sobrevivem próximo ou nas áreas com plantas $B t$ é essencial para detectar a presença da resistência em populações naturais (Tabashnik et al. 2009). Além disso, é importante que os agricultores relatem aos responsáveis pelo programa de manejo da resistência qualquer perda inesperada por ação de predadores nas áreas de cultivo de plantas $B t$.

Para serem efetivos, os programas de monitoramento devem detectar a presença do alelo que confere resistência em frequências muito baixas. Estudos realizados (Huang 2006) indicam que a frequência do alelo para resistência, em geral, é inferior a 0,001 ; nesse caso o número de insetos amostrados em programas de monitoramento deve estar entre 500 e 1000 (US-EPA 2001).

Entre as abordagens possíveis, a Agência de Proteção Ambiental dos Estados Unidos escolhe e utiliza a estratégia de bioensaios de dose resposta e bioensaios de diagnóstico. Esses métodos têm a finalidade de detectar ou monitorar a presença do alelo para resistência produzindo ou detectando a presença de homozigotos recessivos.

Os bioensaios de dose resposta consistem em realizar experimentos procurando detectar diferenças nas doses necessárias para matar as larvas de populações coletadas em campo em relação a populações criadas em laboratório. A sensibilidade desse método é baixa e não detecta a presença de indivíduos resistentes quando sua freqüência é baixa
(Andow \& Alstad 1998). Quando o alelo resistente recessivo é raro será necessário testar milhares de larvas para encontrar uma resistente. A presença de indivíduos resistentes será detectada apenas quando a frequência do alelo para resistência for superior a $40 \%$ ou quando a resistência for herdada como dominante (Venette et al. 2000). Esse método envolve a coleta de insetos em campo, a criação desses em laboratório para produção de descendentes suficientes para a realização dos bioensaios, a realização de uma série de bioensaios expondo os insetos a diferentes concentrações de toxina bt $\mathrm{e}$ as estimativas das doses letais $\left(\mathrm{DL}_{50}, \mathrm{CL}_{50}, \mathrm{DL}_{95}\right.$ e $\left.\mathrm{CL}_{95}\right)$. Os resultados desses experimentos são comparados com dados históricos ou com aqueles obtidos para populações de laboratório (Huang 2006).

Os bioensaios de diagnóstico são baseados em experimentos que utilizam uma dose letal necessária para matar 99\% dos indivíduos susceptíveis; nessa concentração somente os indivíduos resistentes irão sobreviver (Huang 2006). Esse método envolve um único experimento e permite testar um grande número de indivíduos. Segundo Roush \& Miller (1986), quando os indivíduos resistentes corresponderem a $1 \%$ da população, bioensaios com 300 indivíduos têm $95 \%$ de probabilidade de detectar sua presença. Esse método também será mais eficiente quando a resistência for determinada por um alelo dominante; se ela for herdada como recessiva, a frequência do alelo deverá ser superior a 10\% (Venette et al. 2000).

Entre os métodos alternativos, destaca-se aquele denominado de Triagem de F2 (F2 screen), o qual pode detectar a presença de alelos para resistência na população mesmo quando sua frequência é baixa. (Andow \& Alstad 1998, 1999, Andow et al. 2000). O primeiro passo dessa metodologia envolve a coleta de fêmeas grávidas em populações naturais para a criação de populações de iso-linhagens de fêmeas. Os adultos de cada iso-linhagem (F1) irão acasalar entre si para produzir a geração F2. Na teoria, se uma fêmea grávida for heterozigota, 6,25\% dos seus descendentes (F2) poderão ser homozigotos recessivos e, portanto, sobreviver ao tratamento com altas doses de toxina $B t$. Esse método permite detectar a presença do alelo para a resistência mesmo quando é raro na população e também estimar sua frequência (Bourguet et al. 2005, Huang 2006, Xu et al. 2009). 


\section{MANEJO E MONITORAMENTO NO BRASIL}

No Brasil, as principais culturas contendo genes de Bacillus thuringiensis são a do milho e a do algodão; o manejo da resistência para estas plantas é um desafio, pois é preciso conciliar necessidades práticas e as exigências técnicas num ambiente diversificado (Martinelli \& Omoto 2005). Em linhas gerais, as recomendações para manejo e monitoramento da resistência seguem os princípios associados à estratégia de altas doses e refúgios estruturados.

A liberação comercial do algodão $B t$ ocorreu em 2005 (Bollgard ${ }^{\circledR}$ ) e do milho em 2007 (Yeldgard); desde então, para ambas as culturas, outras variedades estão disponíveis como, por exemplo, as variedades de algodão Bollgard $\AA$ II e Widestrike ${ }^{\circledR}$ (Plante Refúgio 2011) e as variedades de milho Agrisure e Herculex (Brescia \& Hélios 2008, Mendes et al. 2009).

As determinações legais para cultivo de plantas transgênicas no Brasil foram definidas pela Resolução Normativa número 4, de 16 de agosto de 2007 (CTNBio). Segundo essa existem duas regras importantes que devem ser seguidas: regra da coexistência e regra do Manejo da Resistência.

Para permitir a coexistência entre uma lavoura comercial de plantas $B t$ e plantas convencionais a regra da coexistência estabelece a distância mínima que deve ser mantida entre as duas áreas cultivadas (Silva et al. 2007).

Para a cultura do milho, as áreas com milho transgênico devem estar a uma distância mínima de cem metros das áreas com milho convencional ou a uma distância de vinte metros; nesse caso, porém, deve ser mantida uma bordadura com, no mínimo, dez fileiras de milho convencional de porte e ciclo vegetativo similar ao milho $B t$. Essa determinação tem por finalidade reduzir a possibilidade de fluxo gênico entre as duas variedades de milho (Brescia \& Helio 2008, CIB 2010, Lourenção et al. 2009, Carneiro et al. 2009).

Para o cultivo de algodão transgênico, a distância mínima é de $800 \mathrm{~m}$ de quaisquer espécies de algodoeiros silvestres ou variedades locais. Além disso, deve manter uma distância mínima de 250 metros de qualquer algodoeiro convencional e implantar bordaduras de contenção de trinta linhas de algodoeiro convencional ao redor das parcelas experimentais na ausência de plantas silvestres ou variedades locais. Estas regras são válidas apenas para aquelas regiões onde é permitido o cultivo de algodão transgênico, como definido pelo Ministério da Agricultura, Pecuária e Abastecimento (MAPA) na Portaria 21 de 2005. As áreas liberadas para cultivo de algodão $B t$ incluem as áreas produtoras de algodão, como Paraná, São Paulo e na zona meridional do Brasil (Barroso et al. 2005, CIB 2009).

Para manejo de evolução da resistência, a manutenção das áreas de refúgio deve corresponder a no mínimo $10 \%$ da área total de cultivo. A definição do tamanho real das áreas de refúgio é uma responsabilidade da empresa e depende das especificidades do produto, ou seja, em alguns casos poderá ser maior que $10 \%$. Os refúgios devem estar localizados a uma distância máxima de 800 metros da área com plantas $B t$ e dever conter plantas de ciclo vegetativo similar ou mais próximo possível da cultivar transgênica. Além disso, as áreas de refúgio devem ser semeadas antes que as áreas com plantas Bt (Mendes et al. 2009, Carneiro et al. 2009).

No Brasil, o monitoramento da suscetibilidade das pragas alvo nas lavouras com plantas $B t$ também é um componente essencial das estratégias de manejo da evolução da resistência, sendo realizado inicialmente pela avaliação do nível de dano das lavouras. Sua finalidade é avaliar a eficiência do programa de manejo e identificar a presença de insetos resistentes nas populações de insetos alvos (Martinelli \& Omoto 2005, Mendes et al. 2009).

Ao adquirir as plantas com genes $B t$ os agricultores assumem um compromisso legal de seguir as determinações para o cultivo destas plantas e ficam cientes das penalidades previstas em lei caso as mesmas não sejam cumpridas.

\section{MANEJO EM PERSPECTIVA}

O desenvolvimento da resistência por parte de pragas alvos é resultante do processo evolutivo. Nossa relação evolutiva com os insetos pragas é denominada, por alguns (Rausher 2001), de coevolução artificial. Essa expressão é utilizada para evidenciar que nossa relação evolutiva com as pragas agrícolas ocorre através das plantas cultivadas. A composição genética das populações de plantas é determinada pelos seres humanos, utilizando processos de melhoramento e de distribuição das sementes (Kareiva 1991). 
Nessa perspectiva, podemos dizer que a espécie humana está envolvida numa corrida ao armamento contra uma diversidade de organismos considerados pragas. A coevolução com as pragas agrícolas é tão relevante que podemos afirmar que o manejo da resistência pode ser considerado um dos grandes problemas que ligam ecologia, evolução e economia na atualidade (Gassman et al. 2009).

As estratégias de controle de pragas utilizam as informações que dispomos sobre os fatores que influenciam o processo de evolução. Mesmo não dispondo de informações precisas sobre todos os fatores envolvidos, utilizamos nossos conhecimentos sobre o processo para definir os procedimentos de manejo que possibilitam manter a eficiência dos métodos empregados no controle de pragas.

$\mathrm{Na}$ primeira década das plantas transgênicas a utilização da estratégia "altas doses e refúgios estruturados" apresentou resultados positivos. Apesar disso, um número significativo de trabalhos registra a presença de genes para resistência em várias espécies (Downes et al. 2010, O'Rourke et al. 2010). Entre as seis principais pragas do algodão analisadas, por exemplo, apenas algumas populações de Helicoverpa zea (Boddie, 1850), apresentaram resistência em campo no Sul dos Estados Unidos (Tabashnik et al. 2008, Tabashnink et al. 2009).

A manutenção das áreas de refúgio é um aspecto fundamental da estratégia que utilizamos para manejar a evolução da resistência de insetos contra as plantas $B t$ Estudos realizados demonstram que na ausência da área de refúgio a resistência a plantas $B t$ evolui rapidamente (Meihls et al. 2008, Lefko et al. 2008, Crowder \& Carriaeré 2009, Lesmesle et al. 2010). As pesquisas que monitoram a evolução da resistência confirmam as principais previsões dos modelos genéticos sobre a importância dos refúgios para o seu manejo. A resistência evolui mais lentamente quando o gene para resistência é recessivo e quando as áreas destinadas aos refúgios aumentam (Tabashnik et al. 2008, 2009, Blanco et al. 2009).

Sendo um componente essencial das estratégias de manejo, a definição do tamanho da área de refúgio é um dos aspectos mais discutidos da "estratégia de altas doses refúgios estruturados". Isso acontece, em parte, pela incerteza que envolve a definição de parâmetros biológicos e genéticos utilizados pelos modelos de simulação que definem os custos e os benefícios associados a essa estratégia. Também influencia esse debate, especialmente por parte dos produtores, os custos envolvidos com a manutenção da área de refúgios, considerada por eles (Vacher et al. 2006), de menor produtividade. Assim, enquanto os pesquisadores se esforçam para definir áreas de refúgios que retardem ao máximo a evolução da resistência mantendo o potencial de controle das plantas $B t$ por mais tempo, os produtores pressionam para sua redução buscando reduzir suas "perdas" a curto prazo (Gressel 2005, Bourguet et al. 2005).

Todos os envolvidos no processo de produção sabem que é impossível produzir alimentos sem custos, ou seja, parte do que plantamos será perdida (pragas, efeitos climáticos). Algumas perguntas para reflexão podem ser destacadas aqui: Quando esse custo pode ser reduzido? Qual o custo aceitável? Qual a participação de cada um dos setores da sociedade na divisão desse custo? Como proceder para que cada setor aceite sua parcela desse custo (educação e/ou legislação)?

O manejo da resistência é um exemplo de como o processo de evolução influencia diretamente a humanidade, mesmo que a maioria dos seres humanos rejeite a idéia de evolução. O crescimento anual de áreas de cultivo com plantas $B t$ aumenta a pressão de seleção para evolução da resistência. Essa observação vale também para as plantas $B t$ da segunda geração que possuem dois ou mais genes $B t$. Nossas estratégias, por mais avançadas que sejam não eliminam a possibilidade do surgimento de insetos resistentes, especialmente quando consideramos o tempo biológico. A história da evolução da resistência aos produtos químicos mostra que a capacidade de adaptação dos insetos é extraordinária (Mallet 1989). Aqui cabe uma pequena pergunta: quantos genes podem ser introduzidos numa planta antes que alterações perceptíveis possam ocorrer no gosto ou na sua qualidade nutricional? Não temos uma resposta para essa pergunta e dificilmente alguém irá respondêla, pelo menos por hora, de forma conclusiva.

A melhor maneira de retardar a evolução da resistência é evitar a exposição desnecessária das populações alvo aos agentes de controle; essa observação é válida para agentes químicos e biológicos (Gusmann et al. 2009, Davies \& Davies 2010). Para que isso seja alcançado, todos os envolvidos no processo devem estar cientes e 
aceitar suas responsabilidades. Assim, quando os conhecimentos que dispomos nos apontam uma estratégia para prolongar a vida útil dos agentes de controle, devemos empregar todos os esforços possíveis para colocá-la em prática. Nesse contexto, a participação dos agricultores é indispensável, pois são eles que devem seguir e monitorar os resultados das estratégias definidas. Para que isso aconteça, além da legislação, é indispensável investir em novas tecnologias e em educação (extensão rural). É preciso aceitar que nossa relação com insetos vai existir por muitas gerações e todos devem dar sua contribuição; e desse modo, minimizar os custos atuais poderá significar um aumento no custo que deverá ser pago pelas próximas gerações.

O desenvolvimento de técnicas de manejo mais precisas depende, também, da ampliação dos conhecimentos sobre os fatores ecológicos e genéticos que influenciam as diferentes espécies de pragas.

\section{CONSIDERAÇÕES FINAIS}

O principal objetivo das estratégias de manejo da evolução da resistência é diminuir a pressão de seleção sobre os indivíduos portadores do gene para resistência, mantendo a frequência destes alelos baixa na população. $\mathrm{Na}$ teoria, a estratégia "altas doses/refúgios estruturados" funciona muito bem, ou seja, dentro das premissas ela realmente reduz a velocidade da evolução da resistência nas populações aumentando, com isso, o tempo de uso das plantas- $B t$. É preciso, no entanto, lembrar que ela é baseada em aceitações que não se aplicam em todas as situações. Estudos sobre o padrão de herança da resistência indicam que outros mecanismos genéticos podem ocorrer, como por exemplo, dominância e herança poligênica (Heckel et al. 2007). Além disso, os cruzamentos podem não ocorrer aleatoriamente; para isso, basta que existam diferenças na velocidade de desenvolvimento entre indivíduos resistentes e susceptíveis. A assincronia no desenvolvimento pode determinar uma frequência maior de cruzamentos entre indivíduos resistentes, o que pode acelerar a evolução da resistência (Liu et al. 2000, Medvinsky et al. 2007).

Não se deve esquecer que as estratégias estabelecidas e aplicadas em países desenvolvidos podem não ser levadas em consideração em países em desenvolvimento. De acordo com High et al. (2004), isso pode ser um problema para a produção de arroz $B t$, especialmente em países onde a adoção de estratégias de manejo da resistência não é obrigatória.

Aadoção de estratégias de manejo e monitoramento da resistência torna-se cada vez mais importante como uma forma de manter por maior período de tempo possível a utilização de plantas $B t$, especialmente quando se observa um crescimento fantástico do cultivo dessas espécies em todo o mundo. Essas estratégias são fundamentais para diminuir a pressão de seleção a favor dos indivíduos portadores do gene para a resistência e também para medidas adicionais de manejo quando a frequência desses genes aumentar em uma população.

\section{REFERÊNCIAS}

ANDOW, D.A. \& ALSTAD, D.N. 1998. The F2 screen for rare resistance alleles. Journal of Economic Entomology, 91: $572-578$.

ANDOW, D.A. \& ALSTAD, D.N. 1999. Credibility interval for rare resistance allele frequencies Journal of Economic Entomology, 92: 755-758.

ANDOW, D.A; OLSON, D.M; HELLMICH, R.L; ALSTAD, D.N \& HUTCHISON W.D. 2000. Frequency of resistance to Bacillus thuringiensis toxin $\mathrm{Cry} 1 \mathrm{Ab}$ in an Iowa population of European corn borer (Lepidoptera: Crambidae). Journal of Economic Entomology, 93: 26-30.

BARROSO, P.A; BARROSO, P.A.V.; FREIRE, E.C.; AMARAL, J.A.B. \& SILVA, M.T. 2005. Zonas de exclusão de algodoeiro transgênico para preservação de espécies de Gossypium nativas ou naturalizadas. Campina Grande, MT: Embrapa Algodão (Embrapa Algodão. Comunicado Técnico, 242). 7 p.

BLANCO, C.A.; FRED GOULD, G.; VEGA-AQUINO, P.; JURAT-FUENTES, J.L.; PERERA, O. P. \& ABEL, G.A. 2009. Bacillus thuringiensis Cry1Ac resistance frequency in tobacco budworm (Lepidoptera: Noctuidae). Journal of Economic Entomology, 102: 381-387.

BOURGUET, D.; DESQUILBET, M. \& LEMARIE, S. 2005. Regulating insect resistance management: the case of non-Bt corn refuges in the US. Journal of Environmental Management, 76(3): 210-220. 
BRESCIA, T. \& HÉLIOS, E. 2008. Prioner responde - milho Bt. http://www.pioneersementes.com.br/InfoTecDownloadDetalhe. aspx? $\mathrm{Id}=183>($ Acesso em janeiro/2011).

CARNEIRO, A.A.; GUIMARÃES, C.T.; VALICENTE, F.H.; WAQUIL, J.M.; VASCONCELOS, M.J.V.; CARNEIRO, N.P. \& MENDES, S.M. 2009. Milho Bt: Teoria e prática da produção de plantas transgênicas resistentes a insetos-praga. Circular Técnica 135 - Embrapa de Sete Lagoas. 26 p.

CAPRIO, M.A. 2001. Source-sink dynamics between transgenic and nontransgenic habitats and their role in the evolution of resistance. Journal of Economic Entomology, 94: 698-705.

COMISSÃO TÉCNICA DE BIOSSEGURANÇA - CTNbio Disponível em:<http://www.ctnbio.gov.br/> (Acesso em junho /2009).

\section{CONSELHO DE INFORMAÇÕES SOBRE BIOTECNOLOGIA}

-CIB. 2009. Guia do algodão: Tecnologia no campo para uma industria de qualidade. http://www.cib.org.br/pdf/ GuiaAlgodaoSet2010.pdf > (Acesso em fevereiro /2011).

\section{CONSELHO DE INFORMAÇÕES SOBRE BIOTECNOLOGIA}

- CIB 2010. Guia do milho: Tecnologia no campo à mesa. http://www.cib.org.br/pdf/GuiaMilhoSet2010.pdf> (Acesso em fevereiro/2011).

CROWDER, D.W. \& CARRIERE, Y. 2009. Comparing the refuge strategy for managing the evolution of insect resistance under different reproductive strategies. Journal of Theoretical Biology 261: 423-430.

DAVIES, J. \& DAVIES, D. 2010. Origins and evolution of antibiotic resistance. Microbiology and Molecular Biology Reviews 74: 417-433.

DOWNES, S.; MAHON, R.J.; ROSSITER, L.; KAUTER, G.; LEVEN, T.; FITT, G. \& BAKER, G. 2010. Adaptive management of pest resistance by Helicoverpa species (Noctuidae) in Australia to the Cry2Ab Bt toxin in Bollgard II cotton. Evolutionary Applications, 3: 574-584.

GASSMANN, A.J.; CARRIERE, Y. \& TABASHNIK, B E. 2009. Fitness costs of insect resistance to Bacillus thuringiensis. Annual Review of Entomology, 54:147-163.

GEORGHIOU, G.P. \& TAYLOR, C.E. 1977. Operational influences in the evolution of insecticide resistance. Journal of Economic Entomology, 70: 653-658.
GOULD, F. 1998. Sustainability of transgenic insecticidal cultivars: integrating pest genetics and ecology. Annual Review of Entomology, 43:701-726.

GRESSEL, J. 2005. Problems in qualifying and quantifying assumptions in plant protection models: Resultant simulations can be mistaken by a factor of million. Crop Protection 24: 1007-1015.

HANUR, V. 2008. Bt resistance and monophagous pests: Handling with prudence. Current Science, 95 (4): 449-451.

HECKEL, D.G.; GAHAN, L.J.; BAXTER, S.W.; ZHAO, J.Z.; SHELTON, A.M.; GOULD, F. \& TABASHNIK, B.E. 2007. The diversity of Bt resistance gene in species of Lepidoptera. Journal of Invertebrate Pathology, 95:192-197.

HIGH, S.M.; COHEN, M.B.; SHU, Q.Y. \& ALTOSAAR, I. 2004. Achieving successful deployment of Bt rice. Trends in Plant Science, 9(6): 286-292.

HUANG, F. 2006. Detection and monitoring of insect resistance to transgenic Bt crops. Insect Science, (13): 73-84.

IVES, A.R. \& ANDOW, D.A. 2002. Evolution of resistance to Bt crops: directional selection in structured environments. Ecology Letters, 5: 792-801.

JAMES, C. 2010. Global Status of Commercialized Biotech/GM Crops: 2009 the first fourteen years, 1996 to 2009. ISAAA Brief 41-2009: Executive Summary.

KAREIVA, P. 1991. Population dynamics in spatially complex environments: Theory and data. Philosophical Transactions of the Royal Society of London B: Biological Sciences, 330: 175190.

LAXMINARAYAN, R. \& FISCHER, C. 2004. Keeping One Row Ahead of the Bugs: The Economics of Pest Resistance to Transgenic Crops Resources, 146 (Fall/Winter): 5-8.

LOURENÇÃO, A.L.F.; BARROS, R. \& MELO, E.P. 2009. Milho Bt: Uso Correto da Tecnologia. Tecnologia e Produção: Milho Safrinha e Culturas de Inverno. ABRASEM. 9p.

LEFKO, S.A.;NOWATZKI, T.M.; THOMPSON, S.D.; BINNING, R.R.; PASCUAL, M.A.; PETERS, M.L.; SIMBRO, E.J. \& STANLEY, B.H. 2008. Characterizing laboratory colonies of western corn rootworm (Coleoptera: Chrysomelidae) selected for survival on maize containing event DAS-59122-7. Journal of Economic Entomology, 132:189-204. 
LEMESLE, V.; MAILLERET, L. \& VAISSAYRE M. 2010. Role of spatial and temporal refuges in the evolution of pest resistance to toxic crops. Acta Biotheoretica, 58: 89-102.

LI, Y.X.; GREENBERG, S.M. \& LIU, T.X. 2006. Effects of Bt expressing Cry1 Ac and Cry2Ab and non-Bt cotton on behavior, survival and development of Trichoplusia ni (Lepidoptera: Noctuidae). Crop Protection 25:940-948.

LIU, Y. B.; TABASHNIK, B. E.; MASSON, L.; ESCRICHE, B. \& FERRE, J. 2000. Binding and toxicity of Bacillus thuringiensis protein Cry1Ca to susceptible and resistant diamondback moth (Lepidoptera: Plutellidae). Journal of Economic Entomology, 93: 1-6.

LIU, Y.B. \& TABASHNIK, B.E. 1997. Experimental evidence that refuges delay insect adaptation to Bacillus thuringiensis. Proceedings of the National Academy of Sciences B: 264: 605-610.

MALLET, J. 1989. The evolution of insecticide resistance: Have the insects won? Trends in Ecology \& Evolution, 4: 336-340.

MARTINELLI, S. \& OMOTO, C. 2006. Resistência de lepidóteros-praga a inseticidas na cultura do algodão no Brasil. Revista Brasileira de Oleaginosas e Fibrosas, 10: 1167-1182.

MEDVINSKY, A.B. GONIK, M.M.; LI, B.L.; MALCHOW, H. 2007. Beyond Bt resistance of pests in the context of population dynamical complexity. Ecological Complexity, 4: 201-211.

MEIHLS, L.N.; HIGDON, M.L.; SIEGFRIED, B.D.; SPENCER, T.A.; MILLER, N.K.; SAPPINGTON, T.W.; ELLERSIECK, M.R. \& HIBBARD B.E. 2008. Increased survival of western corn rootworm on transgenic corn within three generations of on-plant greenhouse selection. Proceedings of the National Academy of Sciences, 105: 19177-19182.

MENDES, S.M.; WAQUIL, J.M. \& VIANA, P.A. 2009 Manejo Integrado de pragas em lavouras plantadas com milho geneticamente modificado com gene bt (Milho Bt). Embrapa Milho e Sorgo. Versão Eletrônica. http://sistemasdeproducao. cnptia.embrapa.br/FontesHTML/Milho/cultivodoMilho_5ed/ milhoBT.htm > (Acesso em fevereiro/2011).

O'ROURKE, M.E.; SAPPINGTON, T.W. \& FLEISCHER, S.J. 2010. Managing resistance to Bt crops in a genetically variable insect herbivore, Ostrinia nubilalis. Ecological Applications, 20(5): 1228-1236.

ONSTAD, D.W.; GUSE, C.A.; PORTER, P.; BUSCHMAN, L.L.; HIGGINS, R.A.; SLODERBECK, P.E.; PEAIRS, F.B.
\& CRONHOLM, G.B. 2002. Modeling the development of resistance by stalk-boring lepidopteran insects (Crambidae) in areas with transgenic corn and frequent insecticide use. Journal of Economic Entomology, 95: 1033-1043.

PLANTE REFÚGIO: Algodão Bt. http://www.planterefugio. com.br/culturas/algodao/. ( Acesso em fevereiro /2011).

PECK, S.L.; GOULD, F. \& ELLNER, S.P. 1999. Spread of resistance in spatially extended regions of transgenic cotton: implications for management of Heliothis virescens (Lepidoptera: Noctuidae). Journal of Economic Entomology, 92: 1-16.

RAUSCHER, M. D. 2001. Co-evolution and plant resistance to natural enemies. Nature, 411:857-864.

ROUSH, R.T. 1994. Managing pests and their resistance to Bacillus thuringiensis: Can transgenic crops be better than sprays? Biocontrol Science and Technology, 4: 501-516.

ROUSH, R.T \& MILLER, G.L. 1986. Considerations for design of insecticide resistance monitoring programs. Journal of Economic Entomology, 79: 293-298.

SHELTON, A.M.; ZHAO, J.-Z. \& ROUSH, R. 2002. Economic, ecological, food safety, and social consequences of the deployment of Bt transgenic plants. Journal of Economic Entomology, 47: $845-881$

SILVA, A.L.L.; WALTER, J.M.; HORBACH, M.A. \& QUORIN, M. 2007. Contenção do fluxo gênico de plantas geneticamente modificadas. Caderno de Pesquisa Série Biologia, 19 (1): 19-26.

TABASHNIK, B.E. \& CARRIERE, Y. 2009. Insect resistance to genetically modified crops. Pp. 74-100. In: A. Gatehouse \& N. Ferry (eds.) Environmental Impact of Genetically Modified and Novel Crops. CABI, Wallingford, UK. 424 p.

TABASHNIK, B.E. \& CROFT, A. 1982. Managing pesticides resistance in crop-arthopod complexes: interactions between biological and operacional fators. Journal of Economic Entomology, 11: 1137-1144.

TABASHNIK, B.E.; GASSMANN, A.J.; CROWDER, D.W. \& CARRIERE, Y. 2008. Insect resistance to Bt Crops: evidence versus theory. Nature Biotechnology, 26: 199-202.

TABASHNIK, B.; VAN RENSBURG, J.B.J. \& CARRIE R.E. Y. 2009. Field-evolved insect resistance to Bt crops: definition, theory, and data. Journal of Economic Entomology, 102(6): 2011-2025. 
MONSANTO. 2010. Technology Use Guide. 2010. < http://www. monsanto.com/monsanto/ag_products/pdf/stewardship/2010 irm_guide.pdf. (Acesso em 09/07/2010).

TYUTYUNOV, Y.V.; ZHADANOVSKAYA, E.A.; ARDITI, R. \& MEDVINSKY, A.B. 2007. A spatial model of the development of pest resistance to a transgenic insecticidal crop: European corn borer on Bt maize. Biophysics, 52: 52-67.

TYUTYUNOV, Y.; ZHADANOVSKAYA, E.; BOURGUET, D. \& ARDITI, R.. 2008. Landscape refuges delay resistance of the European corn borer to Bt-maize: A demo-genetic dynamic model. Theoretical Population Biology, 74(1): 138-146.

US-EPA. 2010. Bt Cotton Refuge Requirements for the 2001 Growing Season. http://www.epa.gov/oppbppd1/biopesticides/ pips/bt_cotton_refuge_2001.html. (Acesso em 09/07/2010).

VACHER, C.; BOURGUET, D.; ROUSSET, F.; CHEVILLON, C. \& HOCHBERG, M.E. Modelling the spatial configuration of refuges for a sustainable control of pests: a case study of $\mathrm{Bt}$ cotton. Journal of Evolutionary Biology, 16: 378-386.

VACHER, C.; BOURGUETS, D.; DESQUILBET, M.; LEMARIE, S.; AMBEC, S. \& HOCHBERG, M.E. 2006. Fees or refuges: which is better for the sustainable management of insect resistance to transgenic Bt corn? Biology. Letter 2: 198-202.

VENETTE, R.C.; HUTCHISON, W.D. \& ANDOW, D.A. 2000. An in-field screen for early detection and monitoring of insect resistance to Bacillus thuringiensis in transgenic crops. Journal of Economic Entomology, 93(4):1055-1064.

WENES, A.L. BOURGUET, D.; ANDOW, D.A.; COURTIN, C.; CARRÉ, G.; LORME, P.; SANCHEZ, L. \& AUGUSTIN, S. 2006. Frequency and fitness cost of resistance to Bacillus thuringiensis in Chrysomela tremulae (Coleoptera: Chrysomelidae). Heredity, 97:127-134.

XU, Z.; LIU, F.; CHEN, J.; HUANG, F.; ANDOW, D.A.; WANG, Y.; ZHU, Y. C. \& SHEN, J. 2009. Using an F2 screen to monitor frequency of resistance alleles to Bt cotton in field populations of Helicoverpa armigera (Hubner) (Lepidoptera: Noctuidae). Pest Management Science, (65): 391-397.

Submetido em 24/11/2010

Aceito em 23/03/2011 